\title{
THE
}

\section{Lithium Salt Effects on Silicon Electrode Performance and Solid Electrolyte Interphase (SEI) Structure, Role of Solution Structure on SEI Formation}

Taeho Yoon

Navid Chapman

University of Rhode Island

Daniel M. Seo

Brett L. Lucht

University of Rhode Island, blucht@uri.edu

Follow this and additional works at: https://digitalcommons.uri.edu/chm_facpubs

Creative Commons License

\section{(c) (i)}

This work is licensed under a Creative Commons Attribution 4.0 License.

\section{Citation/Publisher Attribution}

Yoon, T., Chapman, N., Seo, D. M., \& Lucht, B. L. (2017). Lithium Salt Effects on Silicon Electrode Performance and Solid Electrolyte Interphase (SEI) Structure, Role of Solution Structure on SEI Formation. Journal of The Electrochemical Society, 164(9), A20282-A2088. doi: 10.1149/2.1421709jes Available at: http://dx.doi.org/10.1149/2.1421709jes 


\title{
Lithium Salt Effects on Silicon Electrode Performance and Solid Electrolyte Interphase (SEI) Structure, Role of Solution Structure on SEI Formation
}

\author{
Taeho Yoon, Navid Chapman, Daniel M. Seo, and Brett L. Lucht*,z \\ Department of Chemistry, University of Rhode Island, Kingston, Rhode Island 02881, USA
}

\begin{abstract}
Silicon electrodes were cycled with electrolytes containing different salts to investigate the effect of salt on the electrochemical performance and SEI structure. Comparable capacity retention were observed for the $1.2 M \mathrm{LiPF}_{6}$, $\mathrm{LiTFSI}_{\text {and }} \mathrm{LiClO}_{4}$ electrolytes in ethylene carbonate (EC):dimethyl carbonate (DEC), 1:1, but severe fading was observed for the $1.2 M \mathrm{LiBF}_{4}$ electrolyte. The differential capacity plots and EIS analysis reveals that failure of the $1.2 \mathrm{M} \mathrm{LiBF}_{4}$ electrolyte is attributed to large surface resistance and increasing polarization upon cycling. However, when $\mathrm{LiBF}_{4}$ was added as an electrolyte additive $\left(10 \% \mathrm{LiBF}_{4}\right.$ and $\left.90 \% \mathrm{LiPF}_{6}\right)$, the capacity retention and Coulombic efficiency were improved. The SEI was analyzed by FTIR and XPS for each electrolyte. Both spectroscopic methods suggest that the main components of the SEI are lithium ethylene dicarbonate $(\mathrm{LEDC})$ and $\mathrm{Li}_{2} \mathrm{CO}_{3}$ in the 1.2 $M \mathrm{LiPF}_{6}$, LiTFSI and $\mathrm{LiClO}_{4}$ electrolytes, while an inorganic-rich SEI, composed of LiF and borates, was generated for both the 1.2 $\mathrm{MLiBF}_{4}$ electrolyte and the $10 \% \mathrm{LiBF}_{4}$ electrolyte. The chemical composition of the SEIs and corresponding electrochemical performance of the Si electrodes were strongly correlated with electrolyte solution structure.

(C) The Author(s) 2017. Published by ECS. This is an open access article distributed under the terms of the Creative Commons Attribution 4.0 License (CC BY, http://creativecommons.org/licenses/by/4.0/), which permits unrestricted reuse of the work in any medium, provided the original work is properly cited. [DOI: 10.1149/2.1421709jes] All rights reserved.

(cc) BY
\end{abstract}

Manuscript submitted May 23, 2017; revised manuscript received July 5, 2017. Published July 18, 2017.

Silicon negative electrodes for lithium ion batteries have attracted academic and industrial interest, since they provide $\sim 10$ times more specific capacity $\left(3579 \mathrm{~mA} \mathrm{~g}^{-1}\right)$ than graphite $\left(372 \mathrm{~mA} \mathrm{~g}^{-1}\right)$. However, the large volumetric changes during lithiation and delithiation limits commercial application. ${ }^{1}$ The volume changes result in mechanical stress to individual Si particles and the binder which maintains physical contact between electrode components, thus degenerating the electrode laminate upon repeated lithiation/delithiation. ${ }^{2,3}$ In particular, it has been demonstrated that the electric contact loss becomes severe during delithiation when the Si particles are contracted. Thus, incomplete delithiation due to contact resistance has been reported as one of dominant failure mechanisms. ${ }^{4-7}$ In addition to the volume contraction, the solid electrolyte interphase (SEI) has been reported to be another factor that impedes the reversibility of lithiation. ${ }^{5,7}$ When the SEI on silicon is modified by fluoroethylene carbonate (FEC), the capacity retention, reversibility of lithiation, and suppression of electrolyte decomposition are observed. ${ }^{5,7,8}$ Since the improvement of the SEI is critical for improving the electrochemical performance of Si electrodes, great efforts have been devoted to modify the SEI by using electrolyte additives, surface coatings, or concentrated electrolytes. $^{9-16}$

Recently, it has been reported that the SEI can be significantly modified by changing the electrolyte concentration. ${ }^{16-18}$ For instance, propylene carbonate (PC)-based electrolytes do not generate a stable passivation layer on graphite at low salt concentration. However, upon dissolving high concentrations of either $\mathrm{LiPF}_{6}$ or LiTFSI into PC a $\mathrm{LiF}$ rich passivation layer is generated on graphite affording electrochemical reversibility of the graphite. ${ }^{16,18}$ The change in salt concentration has been reported to result in a change solution structure of the electrolyte. ${ }^{16,19-21}$ In commercial electrolytes for LIBs where the salt concentration is typically $1-1.2 \mathrm{M}$, the solution structure is typically a lithium cation solvated by four solvent molecules and an uncoordinated counter anion. This is referred to as a solvent separated ion pair (SSIP). ${ }^{22-25}$ As the electrolyte concentration is increased, more $\mathrm{PF}_{6}$ anions coordinate to the lithium cations resulting in the formation of a contact ion pair (CIP) or aggregate (AGG). ${ }^{19,20}$ Lower average solvation numbers are observed in electrolytes with high concentrations of CIP or AGG, since the counter ion displaces solvent from the coordination sphere of lithium. We previously reported that the concentration of CIP or AGG in the electrolyte has a strong correlation with the $\mathrm{LiF}$ concentration in the SEI. ${ }^{16}$

\footnotetext{
*Electrochemical Society Member.
}

${ }^{\text {z} E-m a i l: ~ b l u c h t @ c h m . u r i . e d u ~}$
In addition to salt concentration, the association strength of the anion influences the solution structure. ${ }^{19,20,26,27}$ For instance, $\mathrm{LiBF}_{4}$ has a stronger association strength than $\mathrm{LiPF}_{6}, \mathrm{LiClO}_{4}$, and LiTFSI. In $\mathrm{PC}$ or DMC based electrolytes, electrolytes containing $\mathrm{LiBF}_{4}$ have been reported to have lower solvation numbers than comparable electrolytes containing $\mathrm{LiPF}_{6}, \mathrm{LiClO}_{4}$, or LiTFSI, which implies that the $\mathrm{BF}_{4}{ }^{-}$anions more strongly coordinate the lithium cation. ${ }^{19}$ Since the solution structure of the electrolyte influences the composition of the $\mathrm{SEI}, \mathrm{LiBF}_{4}$ containing electrolytes would be expected to have higher concentrations of salt decomposition products, such as $\mathrm{LiF}$ and/or $\mathrm{B}-\mathrm{O} / \mathrm{B}-\mathrm{F}$ containing species, in the SEI.

The effect of changing the lithium salt on SEI structure and function on graphite electrodes has been previously reported. ${ }^{28}$ When ethylene carbonate (EC) based electrolytes containing $\mathrm{LiPF}_{6}$, LiFSI or LiTFSI are used, lithium ethylene dicarbonate (LEDC) is observed as a primary component of the SEI. However, the $\mathrm{LiBF}_{4}$ containing electrolyte results in the generation of an SEI with a high concentration of salt reduction products, which is consistent with the expectation based on solution structure. In this work, silicon electrodes have been cycled with electrolytes containing different salts, $\mathrm{LiPF}_{6}, \mathrm{LiBF}_{4}$, $\mathrm{LiClO}_{4}$, LiTFSI, and a mixture of $10 \% \mathrm{LiBF}_{4}$ and $90 \% \mathrm{LiPF}_{6}$. The electrochemical behavior of the silicon electrodes and corresponding SEI has been investigated with $\mathrm{dQ} / \mathrm{dV}$, EIS, IR and XPS. The $\mathrm{LiBF}_{4}$-containing electrolytes generate a protective SEI enriched in inorganic species such as $\mathrm{LiF}$ and borates. The preferential reduction of the CIP or AGG over SSIP or uncoordinated ethylene carbonate (EC) are discussed.

\section{Experimental}

Silicon nanopowder (Alfar Aeasar), conducting carbon (super C, Timcal), polyacrylic acid (PAA, Aldrich), and carboxymethyl cellulose (CMC, Aldrich) were mixed in deionized water for 3 hours. The composition of $\mathrm{Si}$, carbon, and binder was $50: 25: 25$ by weight ratio. A PAA and CMC mixture (1:1 in weight) was employed for the binder. The as prepared slurry was coated on $\mathrm{Cu}$ foil to prepare an electrode. The laminate electrode was dried in a vacuum oven at $25^{\circ} \mathrm{C}$ overnight and then dried further at $110^{\circ} \mathrm{C}$ for 6 hours. The dried electrode was punched to make disk-shaped electrodes of $14 \mathrm{~mm}$ diameter. Each disk electrode was loaded with $2 \mathrm{mg}$ of $\mathrm{Si} /$ carbon/binder composite.

2032-type coin silicon/lithium cells (half-cells) were fabricated for electrochemical performance testing of the Si electrodes. Two separators (a Celgard 2325 polymer and a Whatman GF/D glass fiber) and $100 \mu \mathrm{L}$ electrolyte were added in each coin half-cell. For electrolyte, 
1.2 $M$ lithium salt $\left(\mathrm{LiPF}_{6}, \mathrm{LiBF}_{4}, \mathrm{LiClO}_{4}\right.$ or $\left.\mathrm{LiTFSI}\right)$ was dissolved in a binary solvent mixture of ethylene carbonate (EC):dimethyl carbonate $(\mathrm{DEC})=1: 1(\mathrm{v} / \mathrm{v})$. In the binary salt electrolyte, $0.12 M(10 \%$ of $\left.1.2 M \mathrm{LiPF}_{6}\right), 0.06 M(5 \%), 0.03 M(2.5 \%)$ or $0.015 M(1.25 \%)$ of $\mathrm{LiPF}_{6}$ was substituted with $\mathrm{LiBF}_{4}$. The total salt concentration was fixed at $1.2 \mathrm{M}$. The electrolytes were assigned as $10 \% \mathrm{LiBF}_{4}$, $5 \% \mathrm{LiBF}_{4}, 2.5 \% \mathrm{LiBF}_{4}$, and $1.25 \% \mathrm{LiBF}_{4}$ according to the $\mathrm{LiBF}_{4}$ concentration.

Galvanostatic lithiation and delithiation were conducted with an Arbin BT2000 battery cycler at $25^{\circ} \mathrm{C}$. The low current density of $\mathrm{C} / 20$ was applied for the $1^{\text {st }}$ cycle and $\mathrm{C} / 3$ for later cycles. Upper and Lower cutoff potentials were $0.6 \mathrm{~V}$ and $0.005 \mathrm{~V}$ respectively. The $\mathrm{C}$-rate was calculated based on an assumption that the Si electrode delivers $3650 \mathrm{mAh} \mathrm{g}^{-1}$. A constant-voltage step, in which the voltage of the $\mathrm{Si}$ electrode is held at $0.005 \mathrm{~V}$, was inserted between lithiation and delithiation steps for compensating capacity loss caused by resistances in lithiation period. The constant voltage was applied until the current density decreases down to $\mathrm{C} / 10$. The electrodes cycled in various electrolytes delivered comparable specific capacity, between $2500 \sim 2800 \mathrm{mAh} \mathrm{g}^{-1}$. Electrochemical impedance spectroscopy (EIS) was measured to monitor impedance variations during cycling. Symmetric cells were assembled with two identical Si electrodes to avoid interference of the Li metal electrode. The potential of the Si half-cells were held at $0.15 \mathrm{~V}$ before being disassembled to minimize SOC deviations between electrodes. The measurements were performed with a Biologic VSP in a frequency range from $300 \mathrm{kHz}$ to $20 \mathrm{mHz}$ and potential amplitude of $10 \mathrm{mV}$.

The surfaces of the cycled electrodes were analyzed by IR and XPS. The Si electrodes were extracted after cycling (delithiation state) and rinsed by using $1 \mathrm{~mL}$ dimethyl carbonate (DMC) 3 times for 1 minute for each rinsing. The extraction and rinsing were conducted in an Ar-filled glove box. The vacuum-dried electrodes were transferred to the instruments with hermetic vessels without air exposure. A Bruker Tensor 27 in attenuated total reflectance (ATR) mode was utilized to obtain IR spectra. The spectra were collected with 256 scans and $4 \mathrm{~cm}^{-1}$ resolution in a continuous $\mathrm{N}_{2}$ flow. OPUS 7.0 software was used for baseline correction and Ge crystal window compensation. The XPS measurements were conducted with a K-alpha (Thermo scientific) XPS with monochromated $\mathrm{Al} \mathrm{K} \alpha$ radiation beam (hv = $1486.6 \mathrm{eV}$ ). The pass energy was $50 \mathrm{eV}$ and the spot size was $400 \mu \mathrm{m}$. The obtained spectra were calibrated with $\mathrm{C}$ 1s hydrocarbon at 284.8 $\mathrm{eV}$. The calibration and fitting were conducted by using Avantage version 5.934

Average solvation numbers of Li cation in electrolytes were determined by IR following a previously reported procedure. ${ }^{19}$ The electrolytes were prepared in an Ar-filled glove box and transferred to a $\mathrm{N}_{2}$-filled glove box containing the IR spectrometer. The scan number was set as 16 to minimize electrolyte evaporation during measurement. The IR spectra were fit by LabSpec Ver. 5.45.09 software.

\section{Results}

Electrochemical analysis.-Four electrolytes, 1.2 M $\mathrm{LiPF}_{6}$, $\mathrm{LiBF}_{4}, \mathrm{LiClO}_{4}$, and LiTFSI in EC/DEC, were investigated to compare the effect of lithium salt on electrochemical performance. The capacity retention of $\mathrm{Si}$ electrodes in the different electrolytes are displayed in Figure 1a. The Si electrodes cycled in the $\mathrm{LiPF}_{6}, \mathrm{LiClO}_{4}$, and LiTFSI electrolytes show comparable capacity retention and Coulombic efficiency while the capacity fades severely for $\mathrm{Si}$ electrodes cycled with the $\mathrm{LiBF}_{4}$ electrolyte. Interestingly, $\mathrm{LiBF}_{4}$ improves the capacity retention and Coulombic efficiency when it is added as an electrolyte additive. The capacity retention of cells with $\mathrm{LiBF}_{4}$ replacing some of the $\mathrm{LiPF}_{6}$, the total concentration of lithium salt was fixed at $1.2 \mathrm{M}$, is provided in Figure 1b. While addition of low concentrations of $\mathrm{LiBF}_{4}$ $(1.25$ or $2.5 \%)$ does not significantly change the capacity retention, higher concentrations of $\mathrm{LiBF}_{4}(5$ or $10 \%)$ provide enhanced capacity retention and Coulombic efficiency. Coulombic efficiencies of $1^{\text {st }}$ cycle and over the $3^{\text {rd }} \sim 60^{\text {th }}$ cycles are summarized in inset tables.
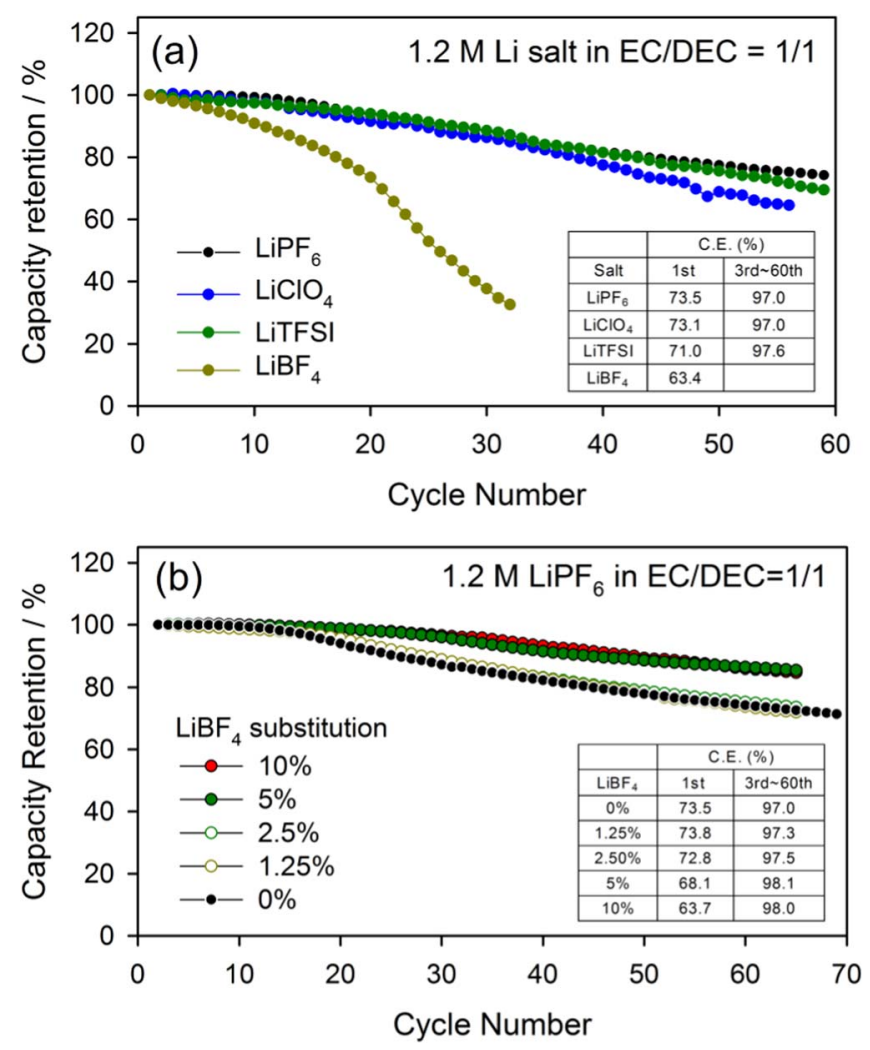

Figure 1. Capacity retentions of Si electrodes cycled with various electrolytes; (a) 1.2 $\mathrm{M}$ of $\mathrm{LiPF}_{6}, \mathrm{LiBF}_{4}, \mathrm{LiClO}_{4}$, and LiTFSI and (b) various $\mathrm{LiBF}_{4}$ concentrations where $\mathrm{LiPF}_{6}$ salt was substituted by $\mathrm{LiBF}_{4}$ and the total lithium salt concentration was fixed at $1.2 \mathrm{M}$. Cut-off potential: $0.6 \sim 0.005 \mathrm{~V}\left(\mathrm{vs} . \mathrm{Li} / \mathrm{Li}^{+}\right)$, C-rate: $\mathrm{C} / 3$.

The Coulombic efficiency of the $\mathrm{LiBF}_{4}$ substituted electrolytes have a clear trend (the inset table in Fig. 2b); a higher concentration of $\mathrm{LiBF}_{4}$ leads to lower Coulombic efficiencies for the $1^{\text {st }}$ cycle, but higher efficiencies during prolonged cycling. The change in Coulombic efficiency implies that $\mathrm{LiBF}_{4}$ participates in electrochemical reactions to generate the SEI on the $1^{\text {st }}$ cycle and that the $\mathrm{LiBF}_{4}$ derived SEI suppresses detrimental side reactions in latter cycles. This suggests that low concentrations of added $\mathrm{LiBF}_{4}$ alter the initial electrochemical reduction reactions of the electrolyte and the structure and function of the SEI. The electrochemical reduction of the $\mathrm{LiBF}_{4}$ substituted electrolytes was further supported with differential capacity $(\mathrm{dQ} / \mathrm{dV})$ plots of the $1^{\text {st }}$ cycles as depicted in Figure 2 . The $d Q / d V$ plots reveal additional reduction reactions at the higher potential in

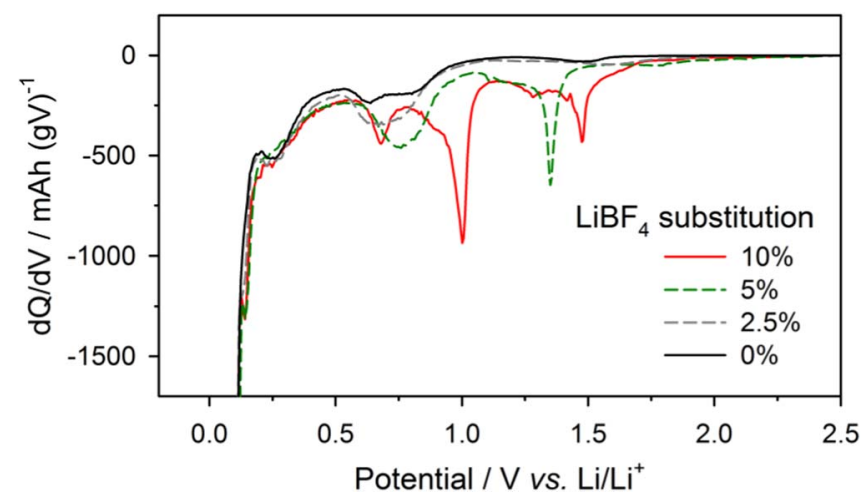

Figure 2. Differential capacity plots of the $1^{\text {st }}$ lithiation in $\mathrm{LiBF}_{4}$-substituted electrolytes. 


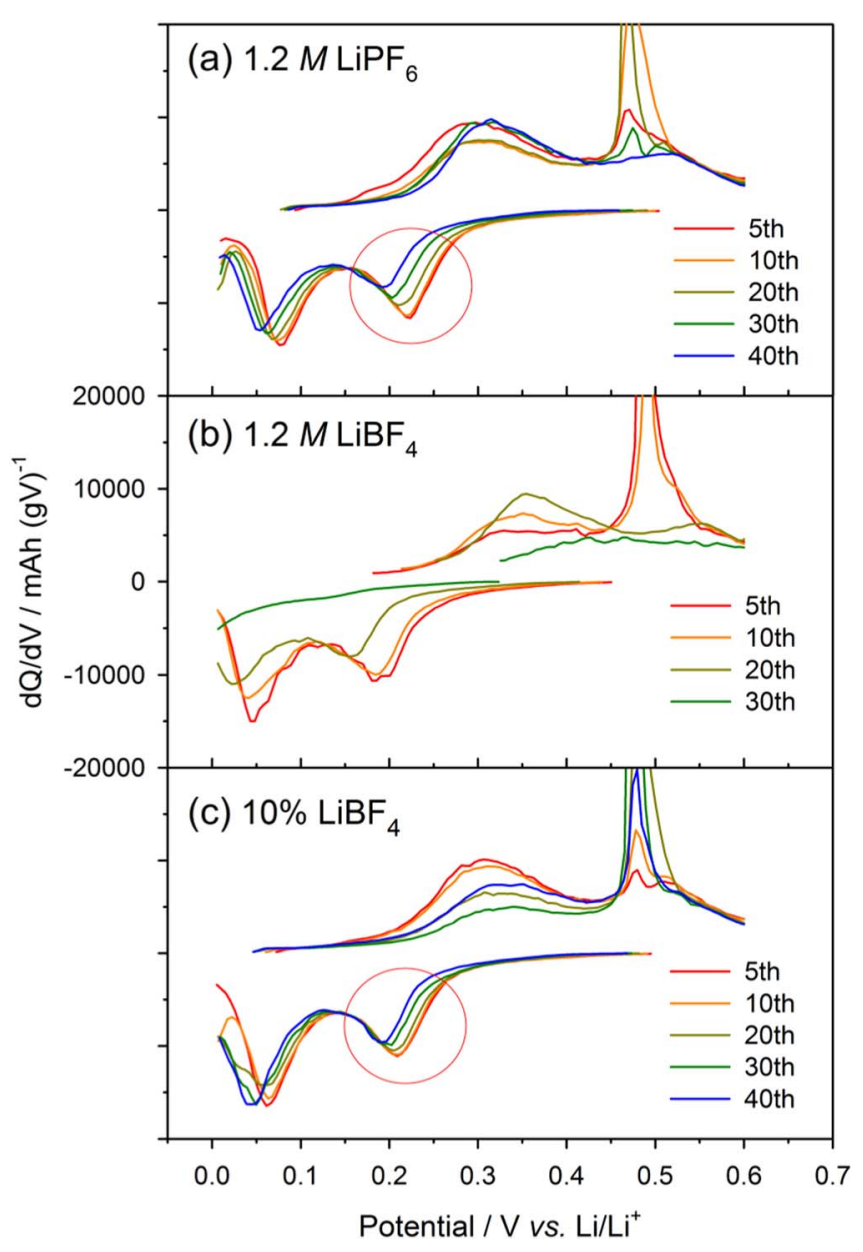

Figure 3. Differential capacity plots of silicon electrodes in various electrolytes; (a) $1.2 M \mathrm{LiPF}_{6}$, (b) $1.2 M \mathrm{LiBF}_{4}$, and (c) $1.08 M \mathrm{LiPF}_{6}+0.12$ $M \mathrm{LiBF}_{4}$. The polarization increase and capacity fade at $0.23 \mathrm{~V}$ (red circle), which indicates incomplete delithiation in previous cycle, were suppressed in the $10 \% \mathrm{LiBF}_{4}$ electrolyte.

electrolytes containing 5 or $10 \% \mathrm{LiBF}_{4}$, correlating with changes in the first cycle Coulombic efficiencies shown in Figure 1b.

The capacity fading behavior was analyzed with $\mathrm{dQ} / \mathrm{dV}$ plots as a function of increasing cycle number (Fig. 3). Two features should be noted in Fig. 3a since they reflect two different capacity fading mechanisms for Si electrodes. First, two peaks are observed at 0.23 and $0.09 \mathrm{~V}$ during lithiation which move to lower potentials during cycling, consistent with polarization increases upon cycling. Due to the polarization increase, the electrode potential during lithiation reaches the cutoff potential earlier than intended and, in turn, the electrode cannot be fully lithiated. However, the capacity loss from the incomplete lithiation is minimized by applying a constant voltage at $5 \mathrm{mV}$ at the end of lithiation. In the constant voltage step, the electrode approaches the thermodynamic state for which it was intended to reach during the constant-current lithiation step. The second characteristic of the dQ/dV plots in Figure $3 \mathrm{a}$ is the decrease of the peak intensity at $0.23 \mathrm{~V}$ as a function of increasing cycle number, while the intensity of the peak at $0.09 \mathrm{~V}$ remains relatively constant. The capacity loss in the earlier region $(\sim 0.23 \mathrm{~V})$ of the lithiation period rather than latter region $(\sim 0.09 \mathrm{~V})$ is attributed to incomplete delithiation in the previous cycles. ${ }^{5}$ The incomplete delithiation is primarily caused by volume contraction. The volume contraction leads to electronic contact loss between silicon, carbon particles and $\mathrm{Cu}$ foil. In addition, it has been demonstrated that the SEI can also contribute to the incomplete delithiation. ${ }^{5,7}$ The contractions of the volume and surface area of $\mathrm{Si}$ results in damage to the SEI, which further increases the contact resis-

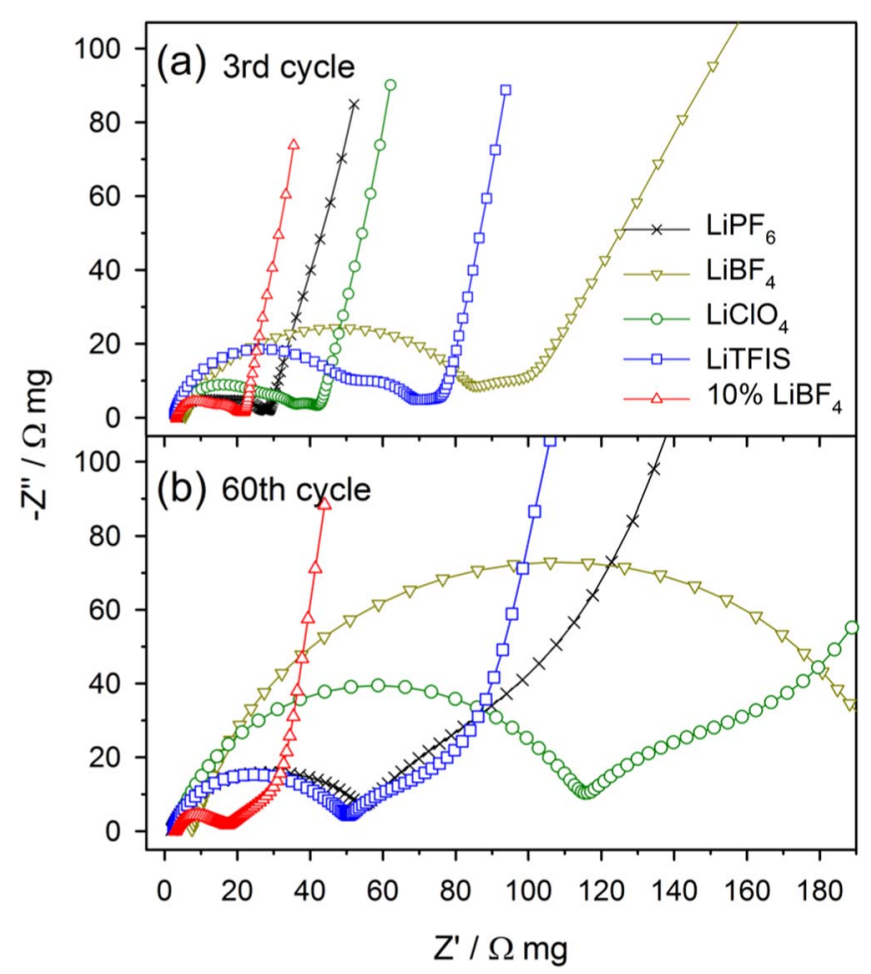

Figure 4. Ac impedance spectra of silicon electrode cycled with various electrolytes; (a) after 3 cycles and (b) 60 cycles. The symmetric cells were prepared for the measurements.

tance and incomplete delithiation. ${ }^{5,7,29}$ The continuous and significant decrease of the peak at $0.23 \mathrm{~V}$ in Fig. $3 \mathrm{a}$ indicates that the incomplete delithiation is the major fading mechanism of the Si electrode. ${ }^{5}$ The $\mathrm{Si}$ electrodes cycled in $\mathrm{LiClO}_{4}$ and LiTFSI have a similar behavior to the $\mathrm{LiPF}_{6}$ electrolyte; incomplete delithiation is a major contributor to capacity fade upon cycling (data are not shown). The $\mathrm{dQ} / \mathrm{dV}$ of the $\mathrm{LiBF}_{4}$ electrolyte in Fig. $3 \mathrm{~b}$ shows severe polarization increase during cycling. Two lithiation peaks shift to lower potentials and are simultaneously decreased upon cycling. The $\mathrm{dQ} / \mathrm{dV}$ implies that the SEI formed in the $\mathrm{LiBF}_{4}$ electrolyte is highly resistive. ${ }^{30,31}$ However, both capacity fading mechanisms, incomplete lithiation and delithiation, are suppressed in the $10 \% \mathrm{LiBF}_{4}$ electrolyte (Fig. 3c). Note that the intensity of the peak at $0.23 \mathrm{~V}$ has better retention, suggesting that the SEI influences the incomplete delithiation, and the SEI generated with the $10 \% \mathrm{LiBF}_{4}$ electrolyte can better accommodate the volume changes of $\mathrm{Si}$ electrode.

EIS measurements were conducted to compare the impedance of the cycled electrodes in the electrolytes. A constant voltage was applied at $0.15 \mathrm{~V}$ to minimize SOC difference between electrodes. And then symmetric cells were built to eliminate the interference of lithium metal electrode. In Figure 4, two semi-circles in high and medium frequency regions are attributed to SEI and charge transfer resistance respectively. A stroke line in the low-frequency region presents Warburg resistance corresponding to lithium ion diffusion in the active material. The SEI and charge transfer resistances are influenced by electrolyte and the summation of the two resistance decreases as an order of $\mathrm{LiBF}_{4}>\mathrm{LiClO}_{4}>\mathrm{LiPF}_{6} \sim \mathrm{LiTFSI}>10 \% \mathrm{LiBF}_{4}$ after 60 cycles, which is consistent with the capacity retentions (Fig. 4b).

Surface analysis.-The silicon electrodes were extracted after 70 cycles and the SEIs formed in the different electrolytes were analyzed by IR and XPS. The IR spectra of the electrodes are provided in Figure 5. The SEIs formed in $\mathrm{LiPF}_{6}, \mathrm{LiClO}_{4}$ and LiTFSI have similar IR spectra which are dominated by LEDC and $\mathrm{Li}_{2} \mathrm{CO}_{3} .{ }^{32-34}$ The characteristic peaks of LEDC are at 1653, 1400, 1315, 1100 and $825 \mathrm{~cm}^{-1}$ and $\mathrm{Li}_{2} \mathrm{CO}_{3}$ are at 1490,1451 and $875 \mathrm{~cm}^{-1} \cdot{ }^{3-36}$ The LEDC is the 


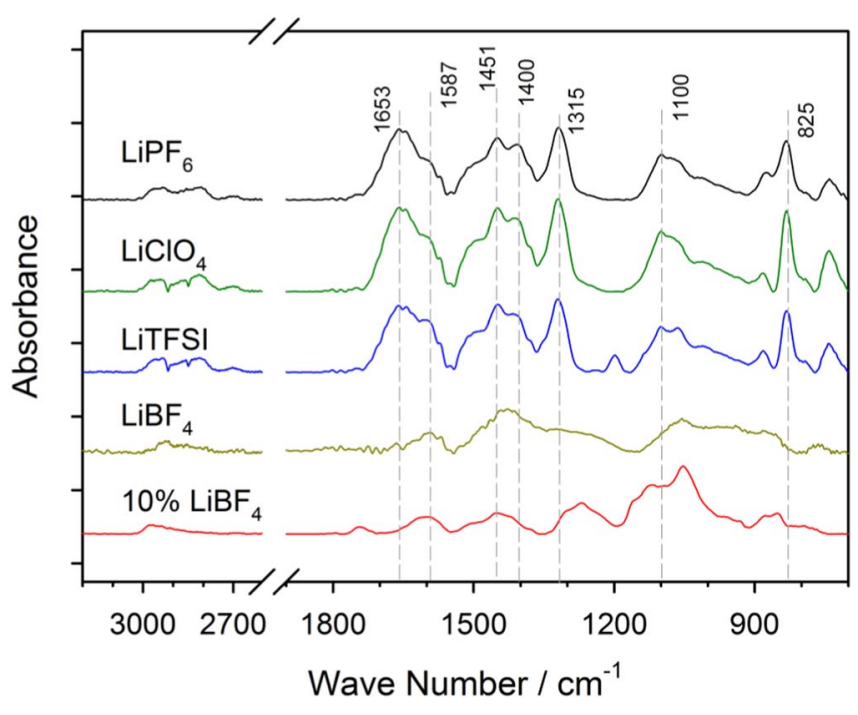

Figure 5. IR spectra of silicon electrodes after 70 cycles in various electrolytes.

primary reduction product of $\mathrm{EC},{ }^{32,37}$ while $\mathrm{Li}_{2} \mathrm{CO}_{3}$ has been reported to be a decomposition product of the LEDC. ${ }^{34}$ The IR spectra imply that the lithium salts, $\mathrm{LiPF}_{6}, \mathrm{LiClO}_{4}$, and LiTFSI, have little influence on $\mathrm{EC}$ reduction. In contrast, the SEI formed in the $\mathrm{LiBF}_{4}$ electrolyte is significantly different. This result is consistent with our previous analysis on graphite electrodes. ${ }^{28}$ The large resistance of $\mathrm{LiBF}_{4}$ derived SEI in Figs. $3 \mathrm{~b}$ and 4 can likely be attributed to the difference in the chemical structure of the SEI. The SEI formed in the $\mathrm{LiBF}_{4}$ electrolyte is highly resistive and has the relatively low concentration of LEDC, which suggests that the SEI generated with the $\mathrm{LiBF}_{4}$ electrolyte suppresses EC reduction. The IR spectrum of the electrode cycled with the $10 \% \mathrm{LiBF}_{4}$ electrolyte, in which $10 \%$ of $\mathrm{LiPF}_{6}$ was replaced by $\mathrm{LiBF}_{4}$, is comparable to the electrode cycled with the $\mathrm{LiBF}_{4}$ electrolyte, indicating that the EC reduction and deposition of LEDC and $\mathrm{Li}_{2} \mathrm{CO}_{3}$ are suppressed. The IR spectra show that upon generation of an SEI with the $\mathrm{LiBF}_{4}$ electrolyte, further reduction of
EC is inhibited. This is well correlated to the Coulombic efficiency and the EIS results.

XPS spectra were obtained from electrodes cycled with the 1.2 $M \mathrm{LiPF}_{6}$ electrolyte and with the $10 \% \mathrm{LiBF}_{4}$ electrolyte. The SEIs deposited on the electrodes are representative of the $\mathrm{EC}$ and $\mathrm{LiBF}_{4}$ derived SEIs, respectively. The $\mathrm{C} 1 \mathrm{~s}$ spectrum of the SEI formed in $\mathrm{LiPF}_{6}$ contains peaks characteristic of $-\mathrm{CO}_{3}$ at $289.9 \mathrm{eV}, \mathrm{C}=\mathrm{O}$ at $288.2 \mathrm{eV}, \mathrm{C}-\mathrm{O}$ at $286.5 \mathrm{eV}$, and C-H/C-C at $284.8 \mathrm{eV}$. ${ }^{8,38}$ The $\mathrm{C} 1 \mathrm{~s}$ spectrum is similar to independently prepared LEDC, indicating that the carbon containing species are dominated by LEDC. ${ }^{34,39}$ However, the electrode cycled with the $10 \% \mathrm{LiBF}_{4}$ electrolyte is dominated by inorganic species from the decomposition products of lithium salts including $\mathrm{LiF}$ (56 eV in $\mathrm{Li} 1 \mathrm{~s}$ and $685 \mathrm{eV}$ in $\mathrm{F} 1 \mathrm{~s}$ ) and borates $\left(191.7 \mathrm{eV}\right.$ in B1s). ${ }^{8,28,40}$ The binding energies used for fitting and corresponding atomic concentrations are summarized in Table I. The SEI generated from the $1.2 \mathrm{MLiPF}_{6}$ electrolyte is composed primarily of carbon, oxygen, and lithium $(\sim 90 \%)$, indicating that the SEI is dominated by LEDC with low concentrations of $\mathrm{LiPF}_{6}$ decomposition products. The SEI generated form the $10 \% \mathrm{LiBF}_{4}$ electrolyte contains a very weak peak characteristic of $-\mathrm{CO}_{3}$ at $289.9 \mathrm{eV}(0.53 \%$, Table I) indicating a very low concentration of $\mathrm{LEDC}$ and $\mathrm{Li}_{2} \mathrm{CO}_{3}$. The atomic concentration suggest that the surface film is mostly composed of inorganic lithium salts, $\mathrm{LiF}$ and borates, from the reduction of $\mathrm{LiBF}_{4}$ and $\mathrm{LiPF}_{6}$.

\section{Discussion}

DFT calculations suggest that the LUMO of the anions, $\mathrm{PF}_{6}{ }^{-}$, $\mathrm{ClO}_{4}{ }^{-}$, $\mathrm{TFSI}^{-}$and $\mathrm{BF}_{4}^{-}$, are higher in energy than the LUMO of EC. ${ }^{41,42}$ This suggests that none of the anions are expected to be electrochemically reduced preferentially to EC, which is consistent with the IR spectra of the electrodes cycled with $\mathrm{LiPF}_{6}, \mathrm{LiClO}_{4}$ and LiTFSI. However, the calculated LUMO energy levels do not explain the significant difference of the SEI formed in the $\mathrm{LiBF}_{4}$ containing electrolytes. The LUMO level of $\mathrm{BF}_{4}{ }^{-}$is comparable to the other anions, suggesting the SEI should be dominated by the EC reduction product, LEDC.

Rather than the reduction potentials of the anions, the solution structures of the electrolytes correlate strongly with the electrochemical performance and SEI compositions. In our previous investigation,

Table I. Atomic concentrations derived from XPS analysis.

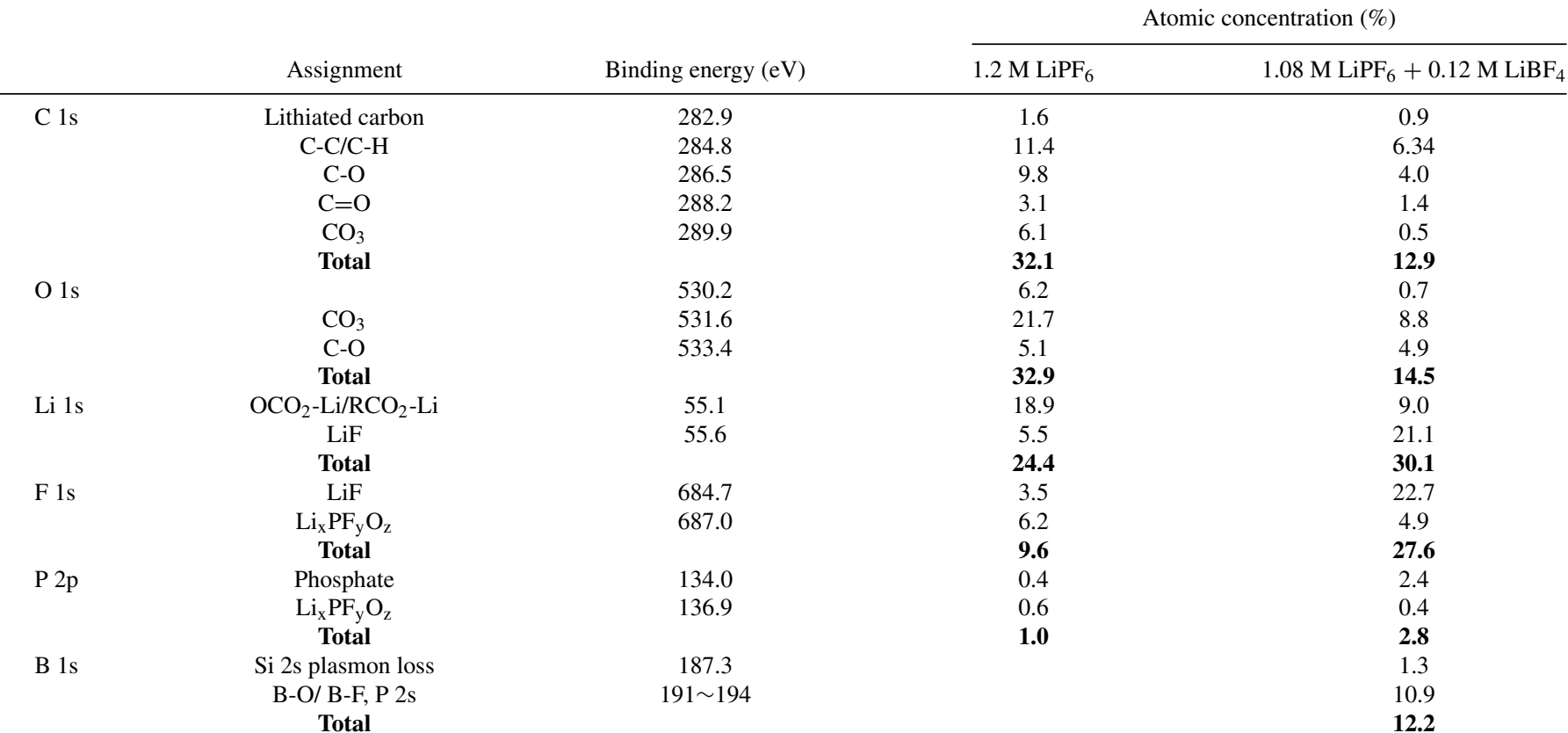



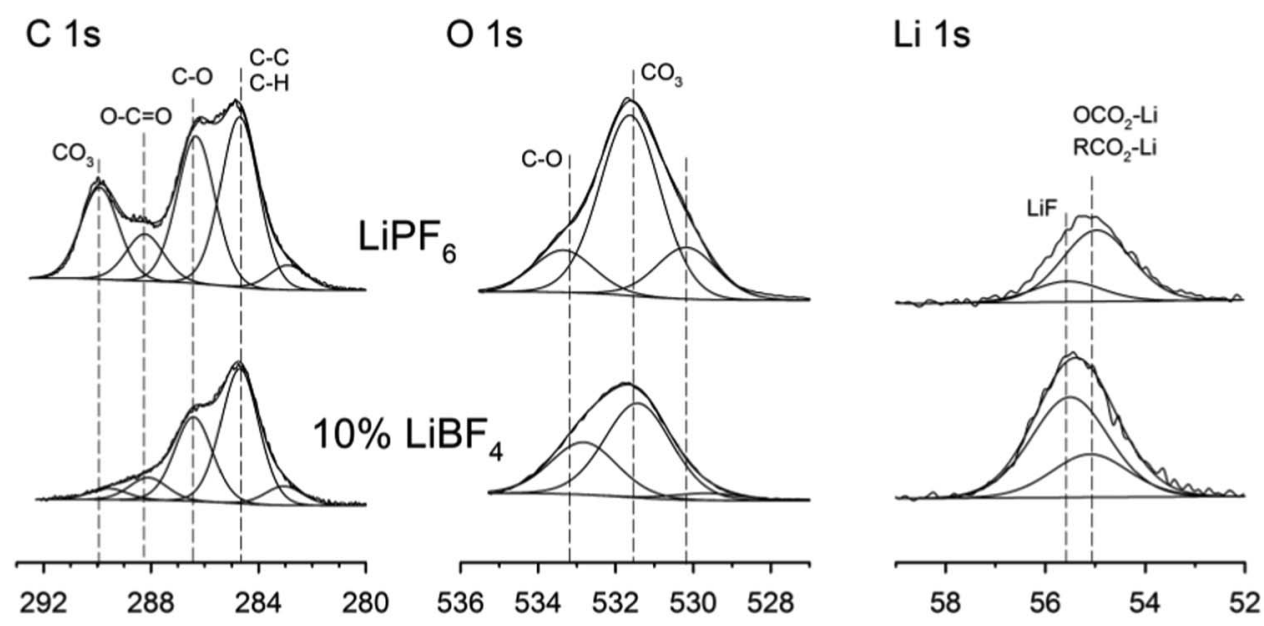

\section{F 1s}

P 2p

B 1s
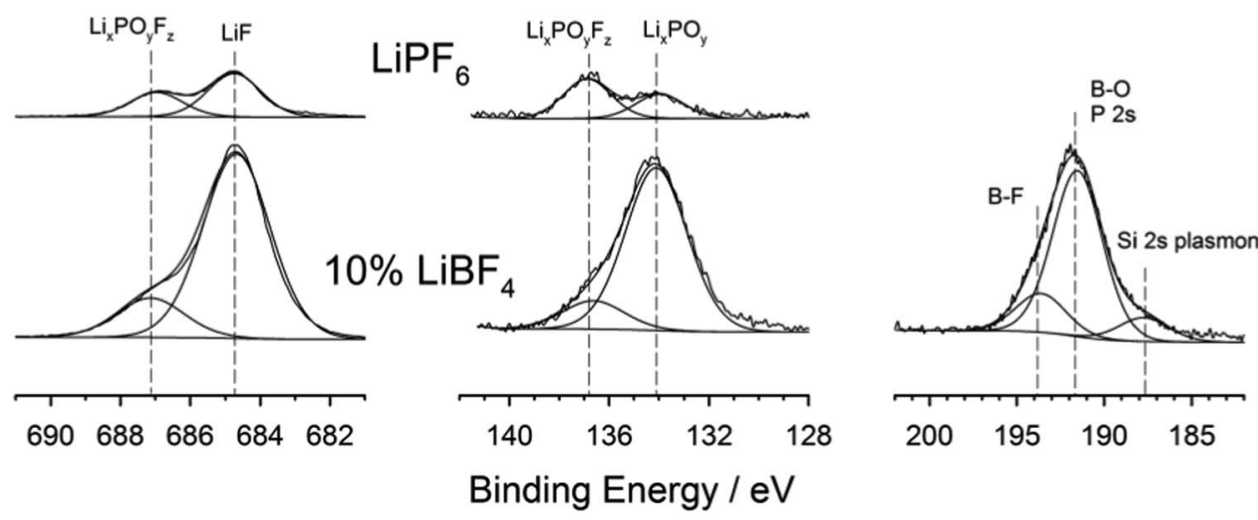

Figure 6. XPS spectra of silicon electrodes after 70 cycles with the $1.2 \mathrm{MLiPF}_{6}$ electrolyte and the $10 \% \mathrm{LiBF}_{4}$ electrolyte.

IR analysis suggests comparable solvation numbers for $\mathrm{LiPF}_{6}$, LiTFSI, and $\mathrm{LiClO}_{4}$, but much lower solvation numbers for $\mathrm{LiBF}_{4}$ in both PC and DMC. ${ }^{19}$ Namely, $\mathrm{LiPF}_{6}$, LiTFSI, and $\mathrm{LiClO}_{4}$ are relatively highly dissociated in the electrolytes, forming primarily SSIP. In contrast, $\mathrm{LiBF}_{4}$ is less dissociated and forms more CIP or AGG with a lower solvation number. ${ }^{19,20,25-27}$ The electrolytes dominated by SSIP, 1.2 $M$ of $\mathrm{LiPF}_{6}$, LiTFSI, or $\mathrm{LiClO}_{4}$, generate predominately LEDC and $\mathrm{Li}_{2} \mathrm{CO}_{3}$ on the $\mathrm{Si}$ surface from the reduction of $\mathrm{EC}$. However,

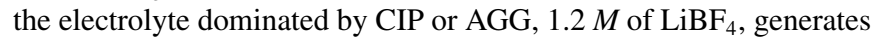
predominantly an inorganic rich SEI from the reduction of the $\mathrm{BF}_{4}$ anion. The capacity retention is comparable for for the $\mathrm{LiPF}_{6}$, LiTFSI, or $\mathrm{LiClO}_{4}$ electrolytes, but the capacity retention is much worse for the $\mathrm{LiBF}_{4}$ electrolyte due to the generation of a very resistive SEI.

To understand the role of solution structure further, the solution structure of the binary salt system was investigated with IR spectroscopy (Figure 7). Some of lithium salt in the $1.2 M \mathrm{LiPF}_{6}, \mathrm{LiClO}_{4}$ or LiTFSI electrolytes was substituted by $\mathrm{LiBF}_{4}$ and the corresponding solvation structure was investigated. When a carbonyl group in a solvent molecule coordinates a lithium cation, the $\mathrm{C}=\mathrm{O}$ band in the IR spectrum shifts to lower wave number. The redshift of the carbonyl peak allows the relative concentrations of the coordinated and uncoordinated carbonate solvents to be determined affording calculation of the solvation number. ${ }^{16,20}$ Unfortunately, the coordinated carbonyl absorption of EC superimposes with the absorption of Fermi resonance of the uncoordinated band, which gives unreliable peak fitting. ${ }^{20}$ Thus, DMC has been selected as a model coordinating solvent since the coordinated/uncoordinated $\mathrm{C}=\mathrm{O}$ bands are clearly distinguishable (Figure 7a). ${ }^{19,20}$ Similar trends have been reported for diethyl carbonate (DEC). ${ }^{20}$ An assumption is made that the lithium ion solvation is dominated by ionic association strength rather than the differences between cyclic or linear carbonate solvents, which is reasonable according to literature..$^{19,20}$ The average solvation number, $N$, was calculated from the relation: ${ }^{19,20,43}$

$$
N \frac{\mathrm{c}_{L i X}}{c_{S o l}}=\frac{A_{C O}}{A_{C O}+A_{U C}}
$$

where $c_{\mathrm{LiX}}$ and $c_{\mathrm{Sol}}$ are the concentrations of the lithium salt and solvent. Since the concentration was fixed at $1.2 \mathrm{M}$, the $c_{\mathrm{LiX}} / c_{\mathrm{Sol}}$ value is constant at $\sim 1 / 7$. $A_{\mathrm{CO}}$ and $A_{\mathrm{UC}}$ are the integrated area of the coordinated and uncoordinated $\mathrm{C}=\mathrm{O}$ bands at 1722 and $1755 \mathrm{~cm}^{-1}$, respectively. The $A_{\mathrm{CO}}$ and $A_{\mathrm{UC}}$ were assumed to have equivalent IR activity. Note that the average solvation number is proportional to the coordinated $\mathrm{C}=\mathrm{O}$ fraction in the equation.

In Figure 7c, the estimated solvation number at $0 \mathrm{M}$ of $\mathrm{LiBF}_{4}$ decreases in the order of $\mathrm{LiPF}_{6}>\mathrm{LiTFSI}>\mathrm{LiClO}_{4}$, which is consistent with our previous results. ${ }^{19}$ Note that the ionic association strength of lithium salts increases in reverse order. The solvation number of each electrolyte decreases with an increase in $\mathrm{LiBF}_{4}$ concentration, approaching the solvation number of the $1.2 \mathrm{MLiBF}_{4}$ electrolyte, 1.65. ${ }^{19}$ The decrease of solvation number implies the replacement of coordinating solvents by anions, resulting in the increase of concentration of CIP and AGG. The concentration of $\mathrm{BF}_{4}{ }^{-}$anions coordinating $\mathrm{Li}^{+}$cations can be estimated for the mixed salt electrolytes. The linear relationship between the solvation number $(N)$ and the concentration 

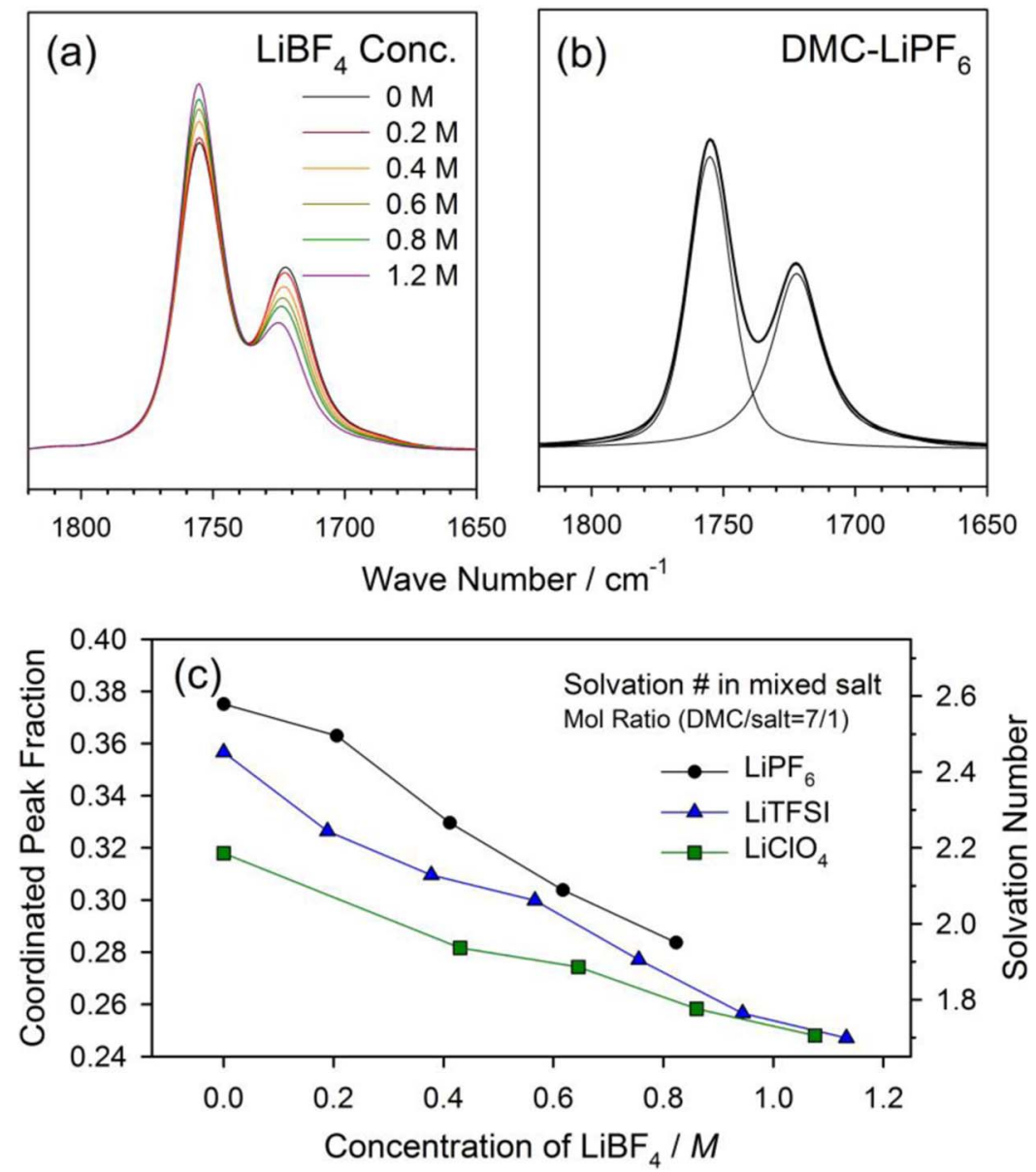

Figure 7. (a) Representative IR spectra of the intensity variations of coordinated $\left(1722 \mathrm{~cm}^{-1}\right)$ and uncoordinated $\mathrm{C}=\mathrm{O}(1755$ $\mathrm{cm}^{-1}$ ) bands with substitution of $\mathrm{LiBF}_{4}$ for $\mathrm{LiPF}_{6}$. (b) Example of spectra fitting of $1.2 \mathrm{MLiPF}_{6}$ in DMC. (c) Calculated coordinated peak fractions and solvation numbers with the $\mathrm{LiBF}_{4}$ substitution in $1.2 M \mathrm{LiPF}_{6}$, LiTFSI, and $\mathrm{LiClO}_{4}$ in $\mathrm{DMC}$. of $\mathrm{LiBF}_{4}\left(C_{\mathrm{LiBF}_{4}}\right)$ shown in Figure 7c is represented by:

$$
N=b-\frac{a}{1.2 M} \cdot C_{\mathrm{LiBF}_{4}}
$$

where $b$ is the solvation number at $0 M \mathrm{LiBF}_{4}, a$ is a coefficient that presents the ratio of $\mathrm{BF}_{4}{ }^{-}$anions which takes part in $\mathrm{Li}^{+}$coordination $(0<a<1)$. Therefore, the term $a \cdot \mathrm{C}_{\mathrm{LiBF}_{4}}$ expresses the concentration of $\mathrm{BF}_{4}{ }^{-}$coordinating $\mathrm{Li}^{+}$, and the term $a \cdot C_{\mathrm{LiBF}_{4}} / 1.2 \mathrm{M}$ is the average number of the coordinating $\mathrm{BF}_{4}{ }^{-}$per $\mathrm{Li}^{+}$cation. In the $\mathrm{LiPF}_{6}-\mathrm{DMC}$ electrolyte, the fit to the equation is $N=2.7-(0.82 / M) \cdot C_{\mathrm{LiBF}_{4}}$, thus $b$ $=2.7$ and $a=0.98$ which indicates that $98 \%$ of the added $\mathrm{BF}_{4}{ }^{-}$anions participate in the $\mathrm{Li}^{+}$coordination. The $a$ value varies in LiTFSI-DMC (0.792) and $\mathrm{LiClO}_{4}-\mathrm{DMC}(0.54)$, which is reasonable since the anions compete for $\mathrm{Li}^{+}$coordination with $\mathrm{BF}_{4}^{-}$. A higher $a$ value, implies a higher population of coordinating $\mathrm{BF}_{4}{ }^{-}$anion, is obtained when $\mathrm{LiBF}_{4}$ is coupled with the salts that have weaker association strength. The solvation numbers obtained from DMC should be smaller than EC (or PC) solvent, but the trend should be comparable. ${ }^{19,20}$

In the $10 \% \mathrm{LiBF}_{4}$ electrolyte, the electrolyte contains $1.08 \mathrm{M}$ of $\mathrm{LiPF}_{6}$ and $0.12 \mathrm{M}$ of $\mathrm{LiBF}_{4}$. While most of the added $\mathrm{BF}_{4}$ anions coordinate lithium ions in the electrolyte, the average solvation number in the $10 \% \mathrm{LiBF}_{4}$ electrolyte in Fig 7c implies that the solution is still dominated by SSIP solvate. However, while the solution is still dominated by SSIP, the concentration of CIP or AGG has been significantly increased since most of the $0.12 \mathrm{M} \mathrm{BF}_{4}{ }^{-}$is coordinated in the form of CIP or AGG. Interestingly, the low concentration of CIP or AGG solvates induces an inorganic-rich SEI which inhibits EC reduction. Thus reduction of the CIP or AGG solvate is more favorable than reduction of the SSIP solvated EC or free EC molecule. It might be attributed to two possibilities; (i) the higher reduction potential of the CIP or AGG solvate, or (ii) lower kinetic barrier for the electron transfer to the CIP or AGG. The preferential reduction of CIP or AGG is consistent with the electrochemical and surface analysis results (Figs. 2, 5 and 6).

The increase of the concentration of CIP or AGG can be achieved by either introducing a strongly associating anion or by concentrating the electrolyte. This suggests that lithium salts with strong ionic association strength could be utilized as additives despite higher LUMO energy levels of the anions. $\mathrm{LiBOB}, \mathrm{LiDFOB}$, and $\mathrm{LiNO}_{3}$, have been previously reported as anionic additives that have the relatively strong ionic association strength, and preferential electrochemical reduction may be related to the presence of CIP or AGG solution structures. ${ }^{44-46}$

\section{Conclusions}

Silicon electrodes were cycled with electrolytes containing different salts; $1.2 M \mathrm{LiPF}_{6}, \mathrm{LiBF}_{4}, \mathrm{LiClO}_{4}$, and LiTFSI in EC/DEC $=1 / 1$ (volume ratio). The electrochemical performance and composition of the SEI for the Si electrodes strongly correlates with electrolyte solution structure. When Si electrodes are cycled with weakly coordinating salts, $\mathrm{LiPF}_{6}, \mathrm{LiTFSI}$, and $\mathrm{LiClO}_{4}$, where the electrolyte is dominated by SSIP, the SEI is dominated by solvent reduction products, $\mathrm{LEDC}$ and $\mathrm{Li}_{2} \mathrm{CO}_{3}$. Alternatively, when $\mathrm{Si}$ electrodes are cycled with a strongly coordinating anion, $\mathrm{LiBF}_{4}$, where the electrolyte is dominated by CIP or AGG, the SEI is dominated by salt reduction products, $\mathrm{LiF}$ and borates. The capacity retention and Coulombic efficiency of Si electrodes cycled with weakly coordinating anions, $\mathrm{LiPF}_{6}, \mathrm{LiTFSI}$, and $\mathrm{LiClO}_{4}$, is good and the electrodes have low impedance. Alternatively, the capacity retention and Coulombic efficiency of $\mathrm{Si}$ electrodes cycled with the strongly coordinating salts, $\mathrm{LiBF}_{4}$, is poor and the electrodes have high impedance which is likely related to a thick SEI composed primarily of inorganic species. When $\mathrm{Si}$ electrodes are cycled with the $10 \% \mathrm{LiBF}_{4}$ electrolyte, the best capacity retention and Coulombic efficiency are observed along with 
the lowest impedance. Surface analysis suggests that the SEI has a high concentration of $\mathrm{LiF}$ and borates. The results suggest that the CIP is electrochemically reduced prior to the SSIP or free solvents and that moderate concentrations of CIP can result in the generation of a modified SEI rich in salt reduction products.

\section{Acknowledgments}

The authors gratefully acknowledge funding from Department of Energy Office of Basic Energy Sciences EPSCoR Implementation award (DE-SC0007074).

\section{References}

1. L. Y. Beaulieu, K. W. Eberman, R. L. Turner, L. J. Krause, and J. R. Dahn, Electrochemical and Solid-State Letters, 4(9), A137 (2001).

2. X. H. Liu, L. Zhong, S. Huang, S. X. Mao, T. Zhu, and J. Y. Huang, Acs Nano, 6(2), 1522 (2012).

3. Z. Chen, L. Christensen, and J. R. Dahn, Electrochemistry Communications, 5(11), 919 (2003)

4. J. H. Ryu, J. W. Kim, Y.-E. Sung, and S. M. Oh, Electrochemical and Solid-State Letters, 7(10), A306 (2004).

5. T. Yoon, C. C. Nguyen, D. M. Seo, and B. L. Lucht, Journal of The Electrochemical Society, 162(12), A2325 (2015).

6. J. G. Lee, J. Kim, H. Park, J. B. Lee, J. H. Ryu, J. J. Kim, and S. M. Oh, Journal of The Electrochemical Society, 162(8), A1579 (2015).

7. J. G. Lee, J. Kim, J. B. Lee, H. Park, H.-S. Kim, J. H. Ryu, D. S. Jung, E. K. Kim, and S. M. Oh, Journal of The Electrochemical Society, 164(1), A6103 (2017).

8. M. Nie, D. P. Abraham, Y. Chen, A. Bose, and B. L. Lucht, The Journal of Physical Chemistry C, 117(26), 13403 (2013).

9. N.-S. Choi, K. H. Yew, K. Y. Lee, M. Sung, H. Kim, and S.-S. Kim, Journal of Power Sources, 161(2), 1254 (2006).

10. K. Xu, Y. Lam, S. S. Zhang, T. R. Jow, and T. B. Curtis, The Journal of Physical Chemistry C, 111(20), 7411 (2007)

11. G.-B. Han, J.-N. Lee, J. W. Choi, and J.-K. Park, Electrochimica Acta, 56(24), 8997 (2011).

12. S. Dalavi, P. Guduru, and B. L. Lucht, Journal of The Electrochemical Society, 159(5), A642 (2012).

13. L. Martin, H. Martinez, M. Ulldemolins, B. Pecquenard, and F. Le Cras, Solid State Ionics, 215(0), 36 (2012).

14. A. von Wald Cresce, O. Borodin, and $\mathrm{K}$. $\mathrm{Xu}$, The Journal of Physical Chemistry C, 116(50), 26111 (2012).

15. D. M. Piper, J. J. Travis, M. Young, S.-B. Son, S. C. Kim, K. H. Oh, S. M. George, C. Ban, and S.-H. Lee, Advanced Materials, 26(10), 1596 (2014).

16. M. Nie, D. P. Abraham, D. M. Seo, Y. Chen, A. Bose, and B. L. Lucht, The Journal of Physical Chemistry C, 117(48), 25381 (2013).

17. S.-K. Jeong, M. Inaba, Y. Iriyama, T. Abe, and Z. Ogumi, Electrochemical and Solid-State Letters, 6(1), A13 (2003).

18. Y. Pan, G. Wang, and B. L. Lucht, Electrochimica Acta, 217269 (2016).
19. N. Chapman, O. Borodin, T. Yoon, C. C. Nguyen, and B. L. Lucht, The Journal of Physical Chemistry C, 121(4), 2135 (2017).

20. D. M. Seo, S. Reininger, M. Kutcher, K. Redmond, W. B. Euler, and B. L. Lucht, The Journal of Physical Chemistry C, 119(25), 14038 (2015).

21. K. D. Fulfer and D. G. Kuroda, The Journal of Physical Chemistry C, 120(42), 24011 (2016).

22. S.-A. Hyodo and K. Okabayashi, Electrochimica Acta, 34(11), 1551 (1989).

23. E. Cazzanelli, F. Croce, G. B. Appetecchi, F. Benevelli, and P. Mustarelli, The Journal of Chemical Physics, 107(15), 5740 (1997).

24. X. Bogle, R. Vazquez, S. Greenbaum, A. V. W. Cresce, and K. Xu, The Journal of Physical Chemistry Letters, 4(10), 1664 (2013).

25. K. Yuan, H. Bian, Y. Shen, B. Jiang, J. Li, Y. Zhang, H. Chen, and J. Zheng, The Journal of Physical Chemistry B, 118(13), 3689 (2014).

26. D. M. Seo, O. Borodin, S.-D. Han, Q. Ly, P. D. Boyle, and W. A. Henderson, Journal of The Electrochemical Society, 159(5), A553 (2012).

27. D. M. Seo, T. Afroz, J. L. Allen, P. D. Boyle, P. C. Trulove, H. C. De Long, and W. A. Henderson, The Journal of Physical Chemistry C, 118(45), 25884 (2014).

28. M. Nie and B. L. Lucht, Journal of the Electrochemical Society, 161(6), A1001 (2014).

29. E. Radvanyi, W. Porcher, E. De Vito, A. Montani, S. Franger, and S. Jouanneau Si Larbi, Physical Chemistry Chemical Physics, 16(32), 17142 (2014).

30. L. D. Ellis, J. Xia, A. J. Louli, and J. R. Dahn, Journal of The Electrochemical Society, 163(8), A1686 (2016).

31. M.-Q. Li, M.-Z. Qu, X.-Y. He, and Z.-L. Yu, Electrochimica Acta, 54(19), 4506 (2009).

32. D. M. Seo, D. Chalasani, B. S. Parimalam, R. Kadam, M. Nie, and B. L. Lucht, ECS Electrochemistry Letters, 3(9), A91 (2014)

33. K. Xu, G. V. Zhuang, J. L. Allen, U. Lee, S. S. Zhang, P. N. Ross, and T. R. Jow, The Journal of Physical Chemistry B, 110(15), 7708 (2006).

34. T. Yoon, M. S. Milien, B. S. Parimalam, and B. L. Lucht, Chemistry of Materials, 29(7), 3237 (2017)

35. P. Verma, P. Maire, and P. Novák, Electrochimica Acta, 55(22), 6332 (2010)

36. S. E. Stein, in NIST Chemistry WebBook, NIST Standard Reference Database Number 69, P. J. Linstrom and W. G. Mallard, eds., National Institute of Standards and Technology, Gaithersburg MD, 20899, Retrieved January 19, 2017.

37. M. Nie, D. Chalasani, D. P. Abraham, Y. Chen, A. Bose, and B. L. Lucht, The Journal of Physical Chemistry C, 117(3), 1257 (2013).

38. B. T. Young, D. R. Heskett, C. C. Nguyen, M. Nie, J. C. Woicik, and B. L. Lucht, ACS Applied Materials \& Interfaces, 7(36), 20004 (2015).

39. R. Dedryvère, L. Gireaud, S. Grugeon, S. Laruelle, J. M. Tarascon, and D. Gonbeau, The Journal of Physical Chemistry B, 109(33), 15868 (2005).

40. I. Gouzman, M. Dubey, M. D. Carolus, J. Schwartz, and S. L. Bernasek, Surface Science, 600(4), 773 (2006).

41. H. Sun and Q. Wei, ECS Transactions, 50(26), 349 (2013).

42. S. P. Ong, O. Andreussi, Y. Wu, N. Marzari, and G. Ceder, Chemistry of Materials, 23(11), 2979 (2011)

43. K. Balasubrahmanyam and G. J. Janz, Journal of the American Chemical Society, 92(14), 4189 (1970).

44. J. L. Allen, D. M. Seo, D. W. McOwen, S.-D. Han, B. A. Knight, P. D. Boyle, and W. A. Henderson, ECS Transactions, 50(26), 381 (2013).

45. W. A. Henderson, The Journal of Physical Chemistry B, 110(26), 13177 (2006).

46. S. H. Kang, D. P. Abraham, A. Xiao, and B. L. Lucht, Journal of Power Sources, 175(1), $526(2008)$ 